\title{
Formulation and Evaluation of Gastroretentive Floating Microspheres of Rilpivirine Hydrochloride
}

\author{
Hyma Ponnaganti ${ }^{1{ }^{*}}$, Ramesh Alluri ${ }^{2}$, Jyothi Vemuri ${ }^{1}$ \\ 'Sarojini Naidu Vanita Pharmacy, Mahavidyalaya, Hyderabad, Telangana, INDIA. \\ ${ }^{2}$ Vishnu institute of Pharmaceutical Education and Research, Hyderabad, Telangana, INDIA.
}

\begin{abstract}
Background: Systems of floating drug delivery have a bulk density less than gastric fluids and thus it remains buoyant in the stomach without having any effect on gastric emptying rate for prolonged period of time. Rilpivirine is an antiviral drug is used to treat human immunodeficiency virus (HIV), to combat the spread of (HIV), delivery of long acting; antiretroviral (ARV) drugs would be very beneficial for prevention and treatment. However the poor bioavailability of the drug requires attention in improving it and the technique of floating microspheres was investigated for the same objective. Methods: Floating microspheres of Rilpivirine are formulated by Emulsion - solvent diffusion technique using Ethyl cellulose and carbopol as polymers. The floating microspheres were subjected to evaluation for micrometric properties, percentage yield, particle size, drug polymer compatibility, scanning electron microscopy (SEM) and in vitro drug release studies and kinetics of drug release. Results: The results show that as the polymer concentration increases, the particle size, percentage yield, in vitro drug release was affected of floating microspheres. The micromeritic
\end{abstract}

test was performed to confirm the particle size, and SEM results confirmed their hollow structure with smooth surface. Optimized formulation has shown good percentage yield, encapsulation efficiency, drug release was $98.25 \%$ at the end of $12 \mathrm{hrs}$, the release was found to follow fickian diffusion with excellent drug release for long period of time. Conclusion: The results conclude that floating microspheres formulation of rilpivirine $\mathrm{HCl}$ could be effective tool in improving the bioavailability of drug for improved absorption. Key words: Rilpivirine $\mathrm{HCl}$, carbopol, floating, microspheres, SEM, antiretroviral.

\section{Correspondence}

Dr. Hyma Ponnaganti,

Sarojini Naidu Vanita Pharmacy, Mahavidyalaya, Hyderabad, Telangana, INDIA.

Email id: rk_hyma@yahoo.com

DOI: 10.5530/ijpi.2021.4.72

\section{INTRODUCTION}

The major drawback of oral drug delivery system is that not all the drug molecules are absorbed uniformly throughout the gastro intestinal tract due to the gastrointestinal tract physiology and transit time that leads to improper bioavailability and non-reproducible therapeutic effects. Hence gastroretentive delivery systems are developed which are a type of control release systems. ${ }^{1}$ It includes floating microspheres which are defined as solid, spherical particles ranging from 1-1000 micrometer in size. They exhibit free flowing nature and powders consisting of synthetic polymers which are biodegradable. Generally prepared by incorporating drug dispersed throughout the matrix that have potential for controlled release of drugs. ${ }^{2}$ Gastroretentive drug delivery (GRDD) is an approach to prolong the gastric residence time, therefore targeting site-specific release of drug in the upper gastrointestinal tract (GIT) for local or systemic effects. ${ }^{3}$ Based on this criteria different approaches have been proposed to retain dosage form in the stomach. ${ }^{4}$

Floating microspheres are a type of gastroretentive systems that are based on non-effervescent approach. The medicament is released gradually at controlled rate, resulting in improved gastric retention with less fluctuations in plasma concentration of drug. ${ }^{5}$ Rilpivirine (RPV) is a next-generation non-nucleoside reverse tran-scriptase inhibitor that has potent activity against wild-type human immunodeficiency virus (HIV) and mutants resistant to first-generation Non-nucleoside reverse transcriptase inhibitors (NNRTIs) and been approved for treatment since 2011. ${ }^{6}$ The physio-chemical and pharmacological properties of RPV have led to exploring the development of a sustained release formulations, aimed at overcoming tedious frequent dosing regimen. ${ }^{7}$
The present work aims at developing a floating drug delivery system of RPV, in form of microspheres using polymers carbopol and ethylcellulose. The solvent evaporation technique was employed for formulation and the formulated microspheres were evaluated to prove the attainment of desired sustained release of the drug with effective drug encapsulation. ${ }^{8}$

\section{MATERIALS AND METHODS}

Materials

Rilpivirine $\mathrm{HCl}$ was gift sample from Hetero Labs Pvt Ltd, polymers and other chemicals were purchased from S.D.Fine chemicals.

\section{Methods}

Organoleptic properties: Colour and nature, taste and odour of the drug were examined.

\section{Identification of drug and excipient compatibility study}

Procedure by FT-IR Studies: The IR spectrums of the rilpivirine $\mathrm{HCl}$ with excipients were taken by using alpha bruker FTIR spectrometer. ${ }^{9}$ The transmission minima obtained in the spectra with the sample corresponded in functional groups position and relative size to those in the spectrum obtained with the standards.

\section{UV Spectroscopic Method for Analysis of Rilpivirine $\mathrm{HCl}$}

Preparation of reagents: Phosphate buffer $\mathrm{pH}$ of 6.8 was prepared by taking $50.0 \mathrm{ml}$ of $0.2 \mathrm{M}$ Potassium dihydrogen phosphate in a $200 \mathrm{ml}$

This is an open access article distributed under the terms of the Creative Commons Attribution-NonCommercial-ShareAlike 4.0 License, which allows others to remix, tweak, and build upon the work non-commercially, as long as the author is credited and the new creations are licensed under the identical terms. 
volumetric flask and add the specified volume of $0.2 \mathrm{M}$ of sodium hydrochloride and then add water to volume.

Standard calibration curve: Stock solution of the drug was prepared by dissolving $100 \mathrm{mg}$ of drug in $100 \mathrm{ml}$ of Phosphate buffer $\mathrm{pH}$ of 6.8 . From this stock solution $2-20 \mu \mathrm{g} / \mathrm{ml}$ concentrations were prepared after suitable dilutions. The absorbance's of each test solutions were checked at $\lambda_{\max }$ of $254 \mathrm{~nm}$ using UV-Visible spectrophotometer against buffer.

\section{Formulation Of Rilpivirine $\mathrm{HCl}$ Floating Microspheres - Formulation design}

Floating microspheres were formulated by Emulsion solvent diffusion. Weighed amount of rilpivirine $\mathrm{HCl}$ was mixed with carbopol and ethyl cellulose Drug and polymers are mixed in a solution of ethanol:dichloromethane at room temperature. Sodium bicarbonate was mixed to above solution. The drug polymer solution was poured slowly in $100 \mathrm{ml}$ of water containing $0.02 \%$ w $/ \mathrm{v}$ Tween 80 maintained at constant temperature of $40^{\circ} \mathrm{C}$ and preparation was stirred at $300 \mathrm{rpm}$ for $1 \mathrm{hr}$. The finely developed microspheres were then filtered, and dried overnight at $40^{\circ} \mathrm{C} .{ }^{10}$

\section{Evaluation of Rilpivirine $\mathrm{HCl}$ Floating microspheres}

Microsphere Particle Size determination: The particle size of the microspheres was determined with an optical microscope under regular polarized light, and mean particle size was calculated by measuring 100 microspheres with the a calibrated ocular micrometer. ${ }^{11}$

\section{Angle of repose}

Angle of repose of microspheres measures the resistance to particles flow, and is determined by fixed funnel method. Where, $(\theta)$ is the angle of repose, H/D is the surface area of standing height of microspheres heap formed paper after dropping the microspheres from glass funnel.

$$
\phi=\tan ^{-1}(\mathrm{~h} / \mathrm{r})
$$

\section{Compressibility Index}

Also called as Carr's index and is determined by following equation.

$$
\text { Carr's Compressibility Index }=\frac{\text { Tapped density }- \text { Bulk density }}{\text { Tapped density }}
$$

\section{Hausner's ratio}

Hausner's ratio is found by the equation.

$$
\text { Hausner's Ratio }=\frac{\text { Tapped density }}{\text { Bulk density }}
$$

\section{Drug Entrapment Efficiency}

The drug content of rilpivirine $\mathrm{HCl}$ loaded microspheres was determined by dispersing $100 \mathrm{mg}$ microspheres in $10 \mathrm{ml}$ of ethanol, which was stirred with a magnetic bead for $8 \mathrm{hr}$ to extract the drug. The samples were diluted and analysed spectrometrically at $254 \mathrm{~nm}$ and the percentage drug entrapment was calculated. ${ }^{12,13}$

$\%$ Drug entrapment efficiency $=\frac{\text { Actual drug content }}{\text { Theoretical drug content }} * 100$

\section{Percentage yield}

The percentage yield was determined by:

$$
\text { Percentage yield }=\frac{\text { Weight of floating microspheres }}{\text { Weight of drug and polymer }}{ }^{*} 100
$$

\section{In vitro Drug Release Study}

In vitro drug release studies of floating microspheres were performed using USP type I dissolution apparatus in $900 \mathrm{ml}$ of Phosphate buffer ( $\mathrm{PH}$ 6.8) dissolution media at $100 \mathrm{rpm}$ and $37^{\circ} \mathrm{C}$. At each specified interval $5 \mathrm{ml}$ of the sample was collected and was replaced by equal volumes of fresh dissolution medium on each occasion. The sample was analyzed by UV Spectrophotometer at $254 \mathrm{~nm}$.

\section{In vitro Release kinetics}

The release data was fitted into various mathematical models. The parameters like ' $\mathrm{n}$ ' and the time component ' $\mathrm{k}$ ' release rate constant and ' $R$ ', which is coefficient of regression are determined by korsmeyerpeppas equation to have an idea on release mechanism. To examine the release mechanism of rilpivirine $\mathrm{HCl}$ from the microspheres, the release data was fitted into Peppa'sequation.

\section{Percentage Buoyancy Rilpivirine HCl Floating Microspheres}

In vitro floating nature can be determined by determining \% buoyancy and carried our in USP type II dissolution apparatus by means of spreading floating microspheres in Phosphate buffer ( $\mathrm{pH}$ 6.8) containing the surfactants. The media stirred at $100 \mathrm{rpm}$ at $37 \pm 0.5^{\circ} \mathrm{C}$. After specific interval of time, samples are collected and analysed for drug release.

\section{Swelling Index}

A $100 \mathrm{mg}$ quantity of microspheres was soaked in $20 \mathrm{~mL}$ of phosphate buffer, pH 6.8 for $12 \mathrm{hr}$. After the $12 \mathrm{hr}$, the microspheres were then removed and excess buffer was wiped using a dry filter paper and their final weights were determined.

$$
\text { Swelling } \operatorname{Index}(\%)=\frac{\text { change in weight }(\mathrm{mg})}{\text { original weight }(\mathrm{mg})} * 100
$$

\section{RESULTS}

\section{Development of Calibration Curve of Rilpivirine $\mathrm{HCl}$}

The standard graph of rilpivirine $\mathrm{HCl}$ was constructed in phosphate buffer, linearity was observed in the absorbance values obtained, hence this curve justifies the analytical method developed for further analysis in in vitro testing studies.

Calibration curve is plotted as shown in Figure 1.

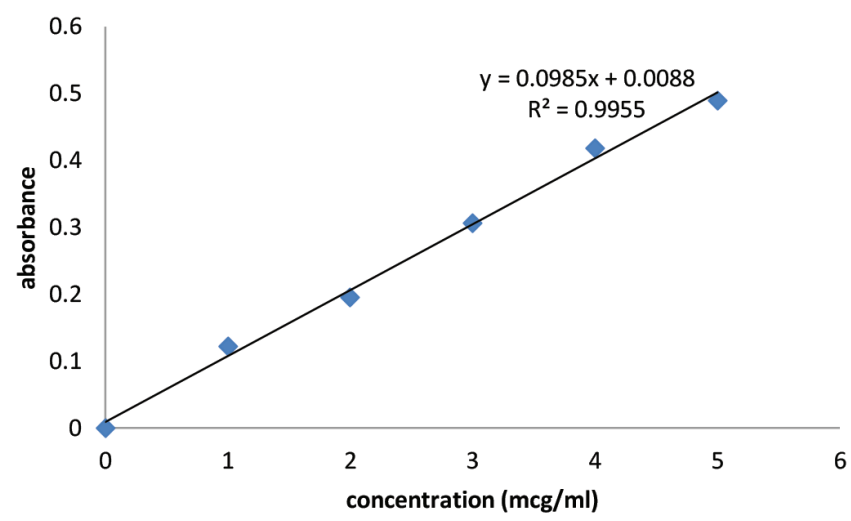

Figure 1: Calibration curve of Rilpivirine $\mathrm{HCl}$. 


\section{Drug-excipients compatibility by FTIR}

The IR spectrum of RPV is characterized by typical absorption bands at about, $1649 \mathrm{~cm}^{-1}(\mathrm{C}=\mathrm{O}$ stretch $), 1430 \mathrm{~cm}^{-1}(\mathrm{C}-\mathrm{H}$ bending $), 1330 \mathrm{~cm}^{-1}(-\mathrm{CH}$ wagging) and $1190 \mathrm{~cm}^{-1}$ (symmetric $\mathrm{C}-\mathrm{N}$ stretching). ${ }^{14}$ There is a decrease of peak intensities observed in optimum formulation and all other peaks of RPV were smooth indicating strong physical interaction of the drug with excipients, same being depicted in Figures 2 and 3.

\section{Percentage yield, Drug Content, Entrapment efficiency, in vitro buoyancy of microspheres of Rilpivirine $\mathrm{HCl}$}

The percentage yield of different formulation was in range $49-88 \%$ as shown in the Table 2. The maximum percentage yield was found in $\mathrm{F}_{4}$. The drug Entrapment efficiency was estimated and the results were in the range of $61-91 \%$. The microspheres formulations F1 to F6 exhibited good floating ability range from $68-92 \%$ (Table 2 ).

\section{The Scanning Electron Microscopy (SEM)}

The micrographs of the microspheres exhibited hollow structure with very smooth surface and exhibited ranges of sizes. Outer surface of microspheres was seem to be smooth, dense whereas the internal surface was found to be porous. The clear morphology with the size ranges is seen in Figure 4.

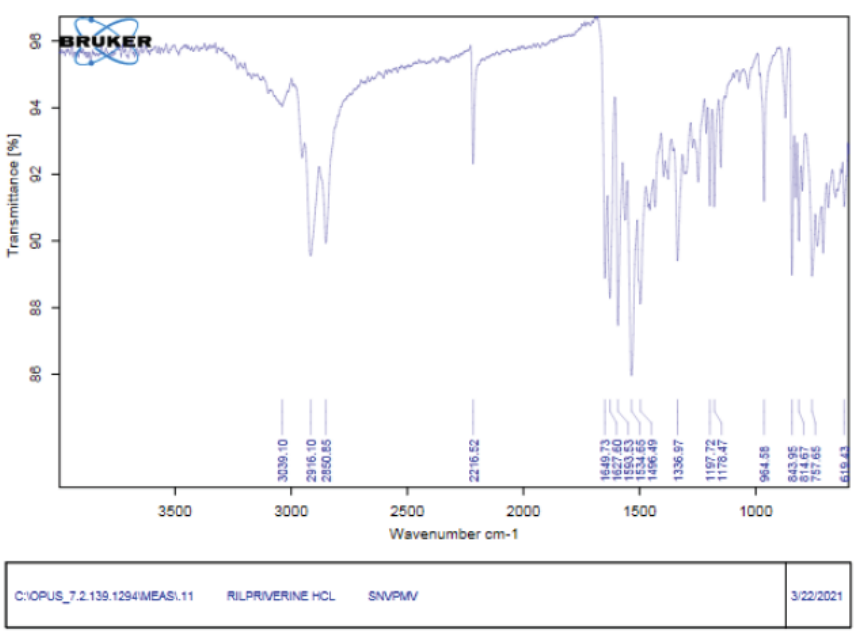

Figure 2: FTIR results of Rilpivirine $\mathrm{HCl}$.

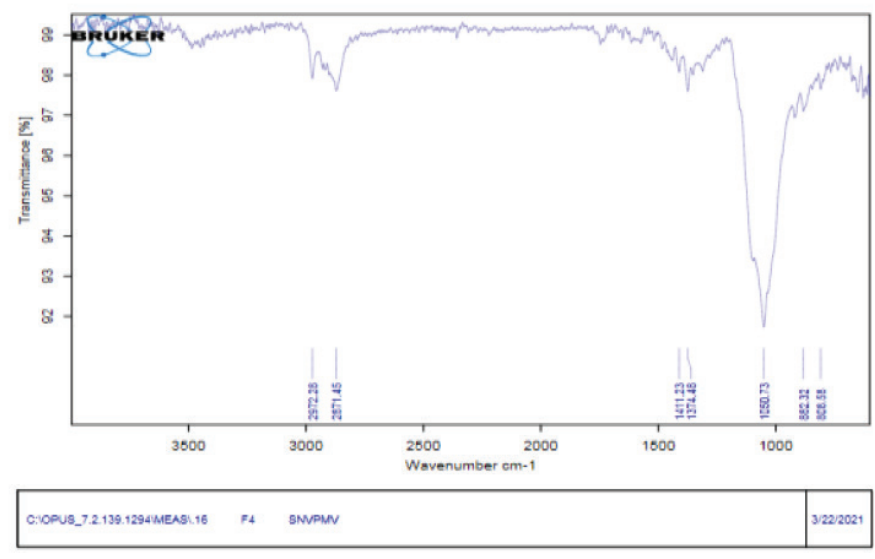

Figure 3: FTIR results of formulation.

\begin{tabular}{|c|c|c|c|c|c|c|c|}
\hline \multirow[b]{2}{*}{ 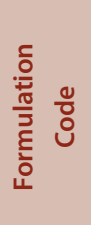 } & \multicolumn{7}{|c|}{ Ingredients } \\
\hline & 올 के & 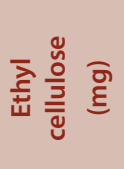 & 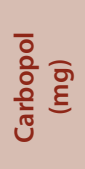 & 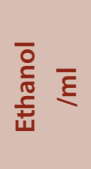 & 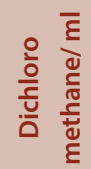 & 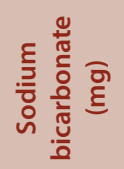 & 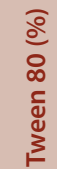 \\
\hline $\mathrm{F} 1$ & 50 & 100 & 100 & 10 & 10 & 100 & 0.02 \\
\hline F2 & 50 & 100 & 200 & 10 & 10 & 100 & 0.02 \\
\hline F3 & 50 & 100 & 300 & 10 & 10 & 100 & 0.02 \\
\hline F4 & 50 & 100 & 400 & 10 & 10 & 100 & 0.02 \\
\hline F5 & 50 & 100 & 500 & 10 & 10 & 100 & 0.02 \\
\hline F6 & 50 & 100 & 600 & 10 & 10 & 100 & 0.02 \\
\hline
\end{tabular}

Table 2: Percentage yield, Drug Content, Entrapment efficiency, Drug release, in vitro buoyancy of microspheres of Rilpivirine $\mathrm{HCl}$.

\begin{tabular}{|c|c|c|c|c|c|}
\hline 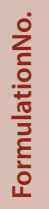 & 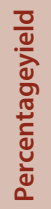 & 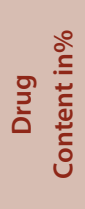 & 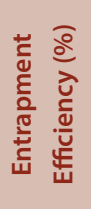 & 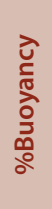 & 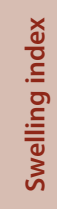 \\
\hline $\mathrm{F} 1$ & 87 & 56 & 66 & 67 & 45.4 \\
\hline F2 & 84 & 67 & 75 & 78 & 67.4 \\
\hline F3 & 96 & 74 & 62 & 86 & 78.2 \\
\hline F4 & 98 & 97 & 93 & 94 & 92.4 \\
\hline F5 & 84 & 88 & 79 & 65 & 56.2 \\
\hline F6 & 83 & 85 & 82 & 78 & 60.2 \\
\hline
\end{tabular}

\section{In vitro drug release studies}

Optimized formulation from the above physical tests $\left(\mathrm{F}_{4}\right)$ showed high release of drug when compared to formulations with other ratio $\left(\mathrm{F}_{1}, \mathrm{~F}_{2}, \mathrm{~F}_{3}\right.$ $\mathrm{F}_{4}, \mathrm{~F}_{5}, \mathrm{~F}_{6}$ ). The graph of cumulative $\% \mathrm{~V} / \mathrm{s}$ time $(\mathrm{min})$ for all formulations was plotted in Figure 2.

\section{DISCUSSION}

In the FTIR studies, there is no additional peaks seen, indicating absence of any chemical interaction. The drug Entrapment determination also showed that the drug was uniformly distributed throughout the preparation. ${ }^{15}$ In vitro buoyancy test was carried out to estimate buoyancy of prepared microspheres. The microspheres formulations F1 to F6 exhibited good floating ability range from $68-92 \%$ (Table 2). The swelling index values indicate excellent absorption of gastric fluids by the polymers to form a swell able polymer sponges which released the drug in sustained effect over long periods of time. ${ }^{16}$ Drug content of different formulation was in range 39\% -91\%. Maximum drug content was found in F4. The microspheres contained planned dose of the drug effectively in optimum ratios of polymers and proper stirring time so as to release drug in sustained manner. (Table 2) The angle of repose of different formulation was in range 2.6-1.7, Bulk and tapped densities showed good pack ability of floating microspheres. The particle size of different formulation was in range $118-122 \%$. The tap density of different formulation was in range $0.20-0.25$. Bulk density of formulation was in range $0.23-0.152$ as shown in Table 3. Release studies of all the formulations of microspheres were conducted in phosphate buffer saline $\mathrm{pH} 6.8$ solution. It was observed 
Table 3: Micrometric properties of floating microspheres of Rilpivirine $\mathrm{HCl}$.

\begin{tabular}{|c|c|c|c|c|c|}
\hline $\begin{array}{l}\frac{5}{0} \\
\frac{0}{\pi} \\
\frac{\pi}{3} \\
\text { है }\end{array}$ & 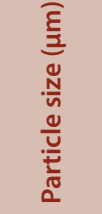 & 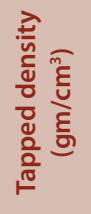 & 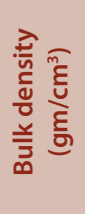 & 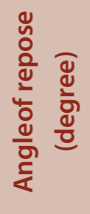 & 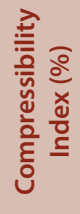 \\
\hline F1 & 158.06 & 0.261 & 0.132 & 2.2 & 33 \\
\hline F2 & 118.06 & 0.250 & 0.120 & 2.3 & 32 \\
\hline F3 & 143.06 & 0.251 & 0.120 & 2.4 & 30 \\
\hline $\mathrm{F} 4$ & 144.04 & 0.252 & 0.121 & 1.5 & 21 \\
\hline F5 & 151.01 & 0.250 & 0.134 & 1.2 & 32 \\
\hline F6 & 136.08 & 0.262 & 0.121 & 1.8 & 22 \\
\hline
\end{tabular}

Table 4: Release Kinetics of Optimised Formulation of $R^{2}$ value.

\begin{tabular}{cccccc}
\hline \multirow{2}{*}{$\begin{array}{c}\text { Formula } \\
\text { code }\end{array}$} & Zeroorder & Firstorder & Higuchi & \multicolumn{2}{c}{ Korsemeyer } \\
\cline { 2 - 6 } & $\boldsymbol{R}^{2}$ & $\boldsymbol{R}^{2}$ & $\boldsymbol{R}^{2}$ & $\boldsymbol{R}^{2}$ & $\mathrm{n}$ \\
\hline $\mathrm{F} 4$ & 0.9336 & 0.9153 & 0.959 & 0.9825 & 0.814 \\
\hline
\end{tabular}

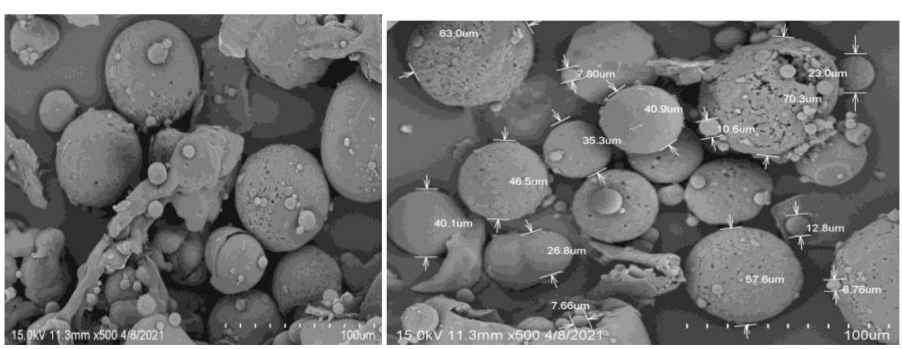

Figure 4: SEM photographs of optimized formulation.

that ratio of drug, ethyl cellulose and carbopol, influences the drug release pattern. ${ }^{17}$ The mechanism of drug release can be analyzed and kinetics of drug release from dosage form can be determined by fitting to various mathematical models such as zero order, First order, Higuchi matrix, and Krosmeyer- Peppas model. The values are depicted below. The $\left(\mathrm{R}^{2}\right)$ was used as an indicator of the best fitting for each of the models. The kinetic data analysis of all the formulations reached higher coefficient of determination with the Korsmeyer-Peppas model ( $R 2=0.914$ to 0.996$)$ whereas release exponent value (n) ranged from 0.498 to 0.743 . From the coefficient of determination and release exponent values, it can be suggested that mechanism of release follows korsmeyer-Peppas model along with non-Fickian diffusion mechanism which leading to the conclusion that a release mechanism of drug followed combination of diffusion and spheres erosion. The formulation of microspheres follows non-fickian diffusion (anamolous). The drug release was found to be by both diffusion as well as erosion. The possible mechanism of action is by Non-fickian (koresmeyer peppas model) and Higuchi matrix model. Morphology of floating microspheres was observed by scanning electron microscopy. Outer surface of microspheres was seem to be smooth, dense whereas the internal surface was found to be porous. Shell of microspheres also exhibited slight porous nature, could be reason of the evaporation of solvent within shell of the microspheres after causing smooth and dense area.

\section{CONCLUSION}

The drug absorption within the GIT is a variable process. This research is undertaken with an aim to plan, formulate and evaluate the novel delivery systems -the floating microspheres. This novel system helps in prolonged gastric retention with extended time for the drug absorption. In this study the floating microspheres of rilpivirine $\mathrm{HCl}$ are prepared and evaluated. They are prepared using the ethyl cellulose in combination with carbopol polymers. The best formulation from the 6 batches (F1 to F6), found to be efficient with good recovery yield, percent drug entrapment and release of drug, was $\mathrm{F} 4$ with drug release of $98.46 \%$.Floating microspheres are evaluated for surface morphology and the surface is found to be smooth. The in vitro drug release kinetics is performed using zero-order, firstorder, Higuchi and korsemeyer models. From the $\mathrm{R}^{2}$ value obtained from korsemeyer peppas method i.e., 0.9825 it is observed that the release of drug is slow and follows Fickian diffusion model.

\section{ACKNOWLEDGEMENT}

I sincerely thank the management of Sarojini naidu vanita pharmacy maha vidyalaya, Hyd. For the encouragement and support and management and principal of Vishnu institute of pharmaceutical sciences for their support during the study.I would also like to thank my mentor and chairman of SNVPMV Dr.B.Prabhashankar sir for his constant guidance in making this research possible and successful.

\section{CONFLICT OF INTEREST}

The authors declare no conflict of interest.

\section{REFERENCES}

1. Dutta P, Sruti J, Niranajan P, Bhanoji. Floating Microspheres: recent trends in the development of gastroretentive floating drug delivery system. Int J Pharm Sci Nanotechnol. 2011;4(1):1296-306.

2. Rajkumar K, Sainath GR, Sai Sowjanya P, Anusha P, Lavanya AS, Reddy ER. Floating microsphere: A novel approach in drug delivery. J Drug Deliv Res. 2012;1(4):1-20.

3. Manjusha AG, Archana KG. A review on floating microspheres as gastroretentive drug delivery system. Am J Pharm Health Res. 2013;1(9):2-21.

4. Mayavanshi AV, Gajjar SS. Floating drug delivery systems to increase gastric retention of drugs: A review. Res J Pharm Technol. 2008;1 (4):345-48.

5. Arora S, Ali J, Ahuja A, Khar RK, Baboota S. Floating drug delivery systems: A review. AAPS Pharm SciTech. 2005;6(3):E372-90. doi: 10.1208/pt060347, PMID 16353995.

6. Margolis DA, Gonzalez-Garcia J, Stellbrink HJ, Eron JJ, Yazdanpanah Y, Podzamczer D, et al. Long-acting intramuscular cabotegravir and rilpivirine in adults with HIV-1 infection (LATTE-2): 96-week results of a randomised, openlabel, phase 2b, non-inferiority trial. Lancet. 2017;390(10101):1499-510. doi: 10.1016/S0140-6736(17)31917-7, PMID 28750935.

7. Satinderkakar RS, Shallusandhan. Gastroretentive Drug Delivery Systems: A review. Afr J Pharm Pharmacol. 2015;9(12):405-17. doi: 10.5897/AJPP2015.4307.

8. Mitsutoshi N, Kikuchi $Y$, Sano $Y$, Nabetani $H$ et al. Continuous manufacturing method for microspheres and apparatus. US patent 6. 2001;177:479

9. Mc Crudden MTC, Larrañeta E, Clark A, Jarrahian C, Rein-Weston A, Lachau-Durand $S$, et al. Design, formulation and evaluation of novel dissolving microarray patches containing a long-acting rilpivirine nanosuspension. J Control Release. 2018;292:119-29. doi: 10.1016/j.jconrel.2018.11.002, PMID 30395897.

10. Jagtap YM, Bhujbal RK, Ranpise NS. Floating microsphere: A review. BJPS. 2012;4(1):17-30

11. Yang Z, Song B, Li Q, Fan H, Ouyang F. Preparation of microspheres with microballoons inside for floating drug-delivery systems. J Appl Polym Sci. 2004;94(1):197-202. doi: 10.1002/app.20856.

12. Rajurkar RM, Rathod CP, Thonte SS, Sugave RV, et al. Gastroretentive mucoadhesive microsphere as carriers in drug delivery: A review. Indo Am J Pharm Res. 2013;3(3):2751-77.

13. Varshosaz J, Tavakoli N, Roozbahani F. Formulation and in vitro characterization of ciprofloxacin floating and bioadhesive extended-release tablets. Drug Deliv. 2006;13(4):277-85. doi: 10.1080/10717540500395106, PMID 16766469. 
14. Kommavarapu P, Maruthapillai A, Palanisamy K, Sunkara M. Preparation and characterization of rilpivirine solid dispersions with the application of enhanced solubility and dissolution rate. Beni-Suef University Journal of Basic and Applied Sciences. 2015;4(1):71-9. doi: 10.1016/j.bjbas.2015.02.010.

15. Singh BN, Kim KH. Floating drug delivery systems: An approach to oral controlled drug delivery via gastric retention. J Control Release. 2000;63(3):235-59. doi: 10.1016/s0168-3659(99)00204-7, PMID 10601721.

16. Jamini M, Rawat S. A review on microsphere, Res J Pharm Boil. Chem Sci.
2013;4(1):1223-33.

17. Gattani YS, Bhagwat DA, Maske AP. Formulation and evaluation of intragastric floating drug delivery system of diltiazem hydrochloride. Asian J Pharm. 2008;2(4):228-31. doi: 10.4103/0973-8398.45036.

18. Jain AK, Jain CP, TanwarYS, Naruka PS. Formulation, characterization and in vitro evaluation of floating microspheres of famotidine as a gastro retentive dosage form. Asian J Pharm. 2009;3(3):222-6. doi: 10.4103/0973-8398.56302.

Article History: Submission Date : 01-09-2021; Revised Date : 18-10-2021; Acceptance Date : 04-11-2021.

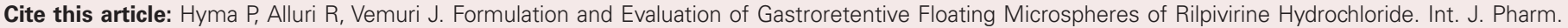
Investigation. 2021;11(4):403-7. 